\title{
Política e reformas fiscais no Brasil recente
}

\author{
Politics and fiscal reforms in recent Brazil
}

\author{
MARIA RITA LOUREIRO * \\ FERNANDO LUIZ ABRUCIO **,***
}

RESUMO: Este estudo enfoca o quadro econômico e político em que ocorreram mudanças fiscais no Brasil nas duas últimas décadas, no contexto geral da reforma do Estado. A ênfase é dada às reformas do governo Cardoso, que são examinadas não apenas do ponto de vista macroeconômico, mas também do ponto de vista da responsabilidade democrática. Sem desconsiderar o papel das conjunturas críticas, o artigo também enfatiza a natureza incremental dessas reformas e indica que as bem-sucedidas ocorrem de forma gradual e que cada passo dado influência o caminho a seguir.

PALAVRAS-CHAVE: Política fiscal, reforma do Estado, responsabilidade; democracia; Brasil.

ABSTRACT: This study focuses on the economic and political framework in which fiscal changes took place in Brazil in the past two decades, in the general context of the State reform. Emphasis is given to the Cardoso government's reforms which are examined not only from a macroeconomic perspective but also from the viewpoint of democratic accountability. Without disregarding the role of critical conjunctures, the article also stresses the incremental nature of these reforms and indicates that successful ones take place gradually and that each step taken has influence on the path ahead.

KEYWORDS: Fiscal policy; State reform; accountability; democracy; Brazil.

JEL Classification: E6; E61.

\section{INTRODUÇÃO}

A reforma do Estado tornou-se tema central na maioria dos países capitalistas, desenvolvidos e em desenvolvimento, a partir da grande crise que atingiu suas economias na década de 1980. A despeito da divergência entre as interpretações,

\footnotetext{
* Professora da Fundação Getúlio Vargas, São Paulo/SP, Brasil. E-mail: mrloureiro@yahoo.com.

* Professor da Fundação Getúlio Vargas, São Paulo/SP, Brasil. E-mail: fabrucio@fgv.br. Submetido: março/2003; aceito: abril/2003.

*** Este artigo é uma versão modificada de trabalho incorporado ao livro O Estado numa Era de Reformas: os anos FHC (no prelo). Os autores agradecem ao Núcleo de Pesquisas e Publicações (NPP) da EAESP-FGV pelo financiamento desta pesquisa.
} 
há razoável consenso de que o aparelho estatal deve ser reestruturado em sua dinâmica interna e em suas relações com a sociedade e o mercado. Nesta nova agenda, a dimensão fiscal tem enorme relevância, tanto no debate da literatura como nos processos efetivos de reformulação da máquina governamental. A discussão deste tema tem sido dominada por economistas e, em menor medida, por cientistas políticos, que norteiam suas análises pelo foco do desempenho econômico e da governabilidade. Procura-se aqui conjugar esses aspectos com outra questão que não é antípoda às anteriores: a importância da negociação e da accountability democrática para o sucesso das reformas fiscais.

De modo geral, a boa gestão fiscal é tida como condição básica para que o Estado estabeleça fundamentos macroeconômicos saudáveis e, assim, consiga favorecer a obtenção de um crescimento econômico sustentável. É esse o pressuposto - correto, diga-se de passagem - que orienta parcela considerável da literatura e dos principais atores políticos. Muitos aspectos influenciam a administração das finanças públicas, como os vetores internacionais, as condições econômicas internas e a história do aparelho estatal em cada país. Todavia, essas variáveis dependem de mecanismos políticos de formulação e implementação, os quais, num regime democrático, são ainda mais importantes e não comportam respostas únicas e lineares.

A variável democrática é duplamente afetada pela questão do ajuste fiscal. De um lado, há os desafios para a governabilidade, uma vez que os governantes em uma ordem democrática, sendo sensíveis às demandas sociais, terão dificuldades de impor o equilíbrio das contas públicas aos seus eleitores: cortes de gastos públicos e/ou elevações de tributos implicam custos políticos elevados e normalmente concentrados, mas benefícios difusos, incertos e de longo prazo (Schick, 1993; Melo, 2002). Tais dificuldades parecem ser ainda mais agravadas em alguns sistemas políticos, como o modelo brasileiro de presidencialismo de coalizão (Abranches,1987). Nele, existem vários pontos de veto no processo decisório (o bicameralismo e o poder dos governos subnacionais, por exemplo), além de ser difícil montar a base de apoio governamental num cenário de fragmentação partidária. Tais características centrífugas, contudo, convivem com fatores centrípetos, como o grande poder do Executivo no âmbito legislativo e no processo orçamentário, a capacidade de interferir nas carreiras dos políticos pela distribuição de cargos, o alto grau de insulamento burocrático em diversas políticas públicas e, ainda, o papel destacado da figura presidencial no sistema político (Loureiro e Abrucio, 1999; Figueiredo e Limongi, 1999).

O enfoque da governabilidade é o mais comum entre os estudos que juntam política e economia no entendimento das reformas do Estado. A preocupação básica dessa linha é avaliar os efeitos de diferentes desenhos institucionais sobre a governabilidade, ou seja, sobre a capacidade dos governos de levar a cabo, ou não, suas políticas públicas em geral ou seus programas de austeridade fiscal, em particular (Weaver e Rockman, 1993; Schick, 1993; Alesina, Roubini e Cohen, 1997).

Em várias ocasiões, as reformas econômicas e os programas de ajuste fiscal podem comprometer princípios democráticos, em especial os de accountability, pois, 
para se obter governabilidade, certos processos de gestão macroeconômica acabam enfraquecendo os mecanismos de responsabilização dos governantes. Isso se dá com a criação de agências insuladas e protegidas das pressões do restante do sistema político, para as quais são indicados agentes não eleitos (burocratas de carreira, acadêmicos ou profissionais do mercado) que são pouco ou nada constrangidos a prestar contas de seus atos ou omissões ante os cidadãos. Na verdade, a perspectiva da accountability democrática têm sido ainda muito pouco desenvolvida na literatura ${ }^{1}$.

O presente estudo pretende contribuir para o avanço desse enfoque teórico por meio da análise das transformações político-institucionais recentes na área fiscal no Brasil, estudando-as não só pelo ângulo de sua consistência macroeconômica e da efetividade de suas políticas, mas igualmente pelo prisma da accountability democrática.

Entende-se por accountability ou responsabilização um processo institucionalizado de controle político estendido no tempo (eleição e mandato) e no qual devem participar, de um modo ou de outro, os cidadãos organizados politicamente. Para tanto, são necessárias regras e arenas nas quais a accountability é exercida, além de práticas de negociação ampliadas entre os atores, para tornar mais públicas e legítimas as decisões.

À noção de responsabilização política, o artigo incorpora a de incrementalismo. Em vez de uma concepção totalizadora de reforma, que supõe a necessidade de uma alteração completa do status quo e a um só tempo, a concepção incrementalista reconhece que mudanças importantes se dão gradualmente e que cada medida tomada e/ou aprovada influencia, em maior ou menor medida, o caminho posterior - é a chamada path dependence, ou histerese, para adequar o sentido original a uma palavra em português. Ocorre algo como uma sedimentação por "camadas geológicas”. Nessa mesma linha, Gerald Caiden constatou que as reformas administrativas pelo mundo afora foram realizadas menos por esquemas grandiosos de transformação e mais por aperfeiçoamento e melhorias substantivas incrementais (Caiden, 1991: 87) ${ }^{2}$.

A ênfase no caráter incremental das reformas não só leva em conta a sua recorrência empírica, como o estudo de Caiden constata para a área administrativa, mas também pressupõe que esse modelo possa conjugar melhor os ângulos do desempenho e da democratização das políticas. O incrementalismo pode ser visto como uma contraposição analítica e normativa em relação à visão totalizadora de

\footnotetext{
${ }^{1}$ São poucos os estudos que procuram examinar como o desenho institucional afeta os mecanismos de responsabilização dos governantes. Vale a pena mencionar aqui a importante coletânea organizada por Przeworski, Stokes e Manin (1999), reunindo ensaios teóricos e estudos empíricos sobre o tema. E ainda o trabalho bastante interessante de Stark e Brustz (1998), sobre as reformas econômicas nos países do Leste Europeu, no pós-socialismo.

${ }^{2}$ Mesmo não aderindo completamente a suas formulações teóricas, cabe lembrar que Douglas Northindica que as mudanças institucionais se processam predominantemente de forma incremental (ver a respeito, North, 1981).
} 
mudança, fundada numa concepção tecnocrática e insulada de reforma. Ao contrário do que supõe essa concepção, a prática incrementalista, ao incluir mais atores e estender no tempo o processo de transformação, não reduz necessariamente a coerência e a consistência dos projetos. Na verdade, ao abrir mais espaços de discussão e fazer as alterações aos poucos, pode-se aprender mais com os possíveis erros de implementação (variável do desempenho) e tornar as decisões mais responsivas e responsáveis (variável democrática) ${ }^{3}$.

Tomando-se como base essa perspectiva teórico-metodológica e analisando-se a experiência brasileira, pode-se sintetizar o argumento central do texto do seguinte modo: observou-se que os pontos bem-sucedidos de transformação das finanças públicas brasileiras, desde a redemocratização, obedeceram a uma lógica basicamente incrementalista, orientada por avanços e recuos nas propostas inicialmente estabelecidas e por negociações com diferentes atores políticos. A cada reformulação realizada, ademais, alterava-se o patamar das discussões posteriores, criando-se uma relação de path dependence. Defendemos que esse modelo incrementalista é o mais compatível com democracias de tipo consensual, como o sistema presidencialista de coalizão existente no Brasil.

$\mathrm{O}$ incrementalismo requer, por um lado, grande capacidade de governança, ou seja, forte competência técnica e articulação gerencial da burocracia governamental, tornando-a capaz de implementar de forma efetiva a agenda do governo. Por outro lado, ele é a expressão de um arranjo institucional no qual o Executivo é forçado a levar em conta e negociar continuamente com outros atores políticos no legislativo e nos governos subnacionais, e até mesmo com grupos organizados na sociedade. Tal enfoque é bastante pertinente ao estudo do caso brasileiro, cujo sistema político se caracteriza pelo consociativismo, para usar expressão de Lipjhart (1999). Presidencialista, multipartidário, federativo, marcado por uma sociedade bem heterogênea, o sistema de poder no Brasil ganha maior legitimidade quanto mais consegue lidar democrática e eficazmente com a sua fragmentação intrínseca. Essa visão se diferencia da maioria da literatura sobre o Brasil, que vê em tais fatores limites à governabilidade e propõe, além do mais, uma lógica mais majoritária de decisão - ou mais centrípeta. Pretendemos mostrar, pela análise das reformas fiscais, que é possível - e desejável — compatibilizar um Executivo forte do ponto de vista da governança e capaz de responder às demandas da maioria com formas mais negociadas e partilhadas de formulação de políticas públicas.

\footnotetext{
${ }^{3}$ Um bom exemplo dessa argumentação está no trabalho de Stark e Brustz (1998). Examinando as ba-ses institucionais da coerência das políticas adotadas no Leste Europeu no pós-socialismo, os autores indicam que a capacidade de elaborar e implementar programas de reforma pode ser aumentada (e não reduzida) quando o Poder Executivo é menos concentrado, ou seja, é mais constrangido a prestar contas de suas decisões às diversas forças políticas no Parlamento e na sociedade organizada. Tendo que debater e negociar suas propostas com outros atores, os decisores aumentam a compreensão dos problemas, ampliam a capacidade de obter informações críticas, corrigindo erros de cálculo que, na ausência deste processo, só apareceriam no momento da implementação e, portanto, com menor possibilidade de correção. Isso encoraja, ainda, os formuladores a pensar vários passos à frente nos jogos estratégicos da política de reforma.
} 
O histórico recente das políticas econômicas brasileiras revela que na maior parte dos casos nos quais o incrementalismo não fora adotado como padrão decisório e de implementação, os resultados acabaram por ser negativos, tanto para o desempenho econômico como para a accountability democrática. Exemplos paradigmáticos são os planos econômicos heterodoxos, como o Cruzado ou o Collor I, que misturavam insulamento burocrático, hiperatividade decisória e, em certos casos, condução presidencial personalista, com conseqüências distantes tanto da responsabilização como da eficácia política. Exatamente por fugir desse modelo foi que o Plano Real deu certo. Sua novidade estava na mistura de policy learning, pois muitos dos técnicos haviam participado e aprendido com os planos anteriores, com uma visão antípoda à do choque, já que por cinco meses, da implantação da URV à respectiva criação da nova moeda, a estabilização monetária foi implantada aos poucos, sem surpresas ou rompimentos de contratos. Gradualmente os atores sociais adaptavam-se à transformação da realidade econômica e sinalizavam suas preferências ao Governo Federal, que podia assim testar melhor o desempenho da política e corrigi-la, caso fosse necessário (Loureiro, 1997; Couto e Abrucio, 1999).

Por fim, é preciso deixar claro que a ênfase aqui atribuída à perspectiva incrementalista não implica desconsiderar a existência de "conjunturas críticas", as quais geram pontos de inflexão nos processos de mudança política (Pierson, 2000). São momentos históricos decisivos ou "maquiavelianos", para utilizar a expressão de Pocock (1975), nos quais a posição relativa dos atores, em termos de poder e preferências, é modificada. Com isso, novos parâmetros orientadores das ações coletivas são introduzidos. No caso brasileiro, podemos citar o Plano Real como uma conjuntura crítica (Sola e Kugelmas: 2002), a partir da qual o grupo liderado por Fernando Henrique Cardoso - primeiro como ministro (e, adiante, como "quase" primeiro-ministro), depois como presidente - conseguiu aumentar seu poderio e, desse modo, derrubou alguns obstáculos que impediam a realização de certas reformas, como a variável federativa no caso da renegociação das dívidas estaduais.

O texto que se segue está estruturado em três partes. Na primeira, analisamos o quadro econômico e político no qual se processam as transformações na ordem fiscal no Brasil ao longo das duas últimas décadas e no contexto geral da reforma do Estado. Ênfase especial é atribuída ao papel central do ajuste fiscal na agenda do governo FHC. Na parte II, tais mudanças são examinadas sob o prisma da problemática da accountability, observando-se duas áreas relevantes: a que abarca as novas regras relativas ao endividamento público, criadas pelo Senado Federal, e a Lei de Responsabilidade Fiscal (LRF). Por fim, apresentamos as considerações finais que sintetizam as análises e apontam algumas perspectivas para o atual governo na área fiscal. 


\section{CONTEXTO MACROECONÔMICO E POLÍTICO \\ DAS TRANSFORMAÇÕES FISCAIS NO BRASIL: \\ DOS ANOS 80 ÀS MUDANÇAS DA ERA FHC}

O processo de transformação mais recente das finanças públicas tem início na crise da dívida externa, em 1982, quando o modelo de financiamento e organização do Estado nacional desenvolvimentista foi colocado em xeque. No campo mais específico, havia uma forte desorganização: além da existência de numerosos orçamentos públicos, havia duas autoridades monetárias em concorrência (Banco do Brasil e Banco Central), que também exerciam a função de bancos de fomento ao desenvolvimento econômico (OCDE, Brasil 2001). Tal situação de desordenamento das contas públicas foi acentuada pelo caráter autoritário do regime militar, dado que não havia controle público democrático das decisões altamente insuladas tomadas pela tecnocracia econômica. Destacamos essa situação histórica para reforçar nosso argumento de que a qualidade democrática do processo decisório tem efeitos positivos sobre o desempenho das políticas macroeconômicas. Dito de outro modo: se a democracia não é condição suficiente para o sucesso econômico, ela é, porém, condição necessária.

Com a redemocratização, várias pequenas reformas foram feitas, imprimindo um caráter incremental à transformação das finanças públicas. A extinção da "contamovimento" e do Orçamento Monetário, bem como a criação da Secretaria do Tesouro Nacional, enquadram-se nesse processo (Gouvea, 1994), favorecendo não só o ordenamento das contas públicas no país, mas igualmente a centralização da autoridade monetária no Banco Central.

Os efeitos de tais mudanças institucionais nas finanças públicas foram, no entanto, razoavelmente neutralizados por dois fatores principais: o processo superinflacionário, que durou até 1994, e o contexto de relações financeiras predatórias entre União e governos subnacionais. No que se refere ao primeiro aspecto, somente com o Plano Real, após várias tentativas de estabilização econômica, é que se conseguiu atacar o caráter inercial da inflação. Esse sucesso, como veremos, alterou a posição relativa dos atores, tal qual uma conjuntura crítica, mas também se alimentou de outras mudanças incrementais nas finanças públicas.

Do ponto de vista das relações financeiras intergovernamentais, os governos subnacionais fortaleceram-se ao longo da redemocratização do país, conquistando uma nova posição quanto à repartição de recursos e à autonomia tributária (Abrucio, 1998). A Constituição de 1988 é o corolário desse processo. Só que essa mudança não foi acompanhada pela criação de responsabilidade federativa no campo fiscal. Estados e municípios endividaram-se com a certeza de que a União socorreria a todos e, de fato, esses débitos foram sistematicamente renegociados. De 1988 a 1997, houve sete acordos de negociação das dívidas entre o Governo Federal e os governos estaduais, os quais, na maioria dos casos, não eram cumpridos. O pior de tudo é que não havia punição para aqueles que descumpriam tais contratos, muito menos recompensas para os que seguiam à risca as regras (Werneck, 1998).

Estabeleceu-se, portanto, uma situação de moral hazard no relacionamento 
entre a União e os governos subnacionais. Três artifícios deram base a esse comportamento por parte de estados e municípios:

a) receitas extraordinárias geradas pelo chamado "imposto inflacionário",oriundo tanto de reajustes da folha de pessoal em níveis inferiores à taxa de inflação quanto do prolongamento dos prazos de pagamento de credores;

b) uso dos bancos estaduais como mecanismo (não legal) de "quase-emissão"de moeda, pela prática reiterada de o governo não saldar as dívidas contraídas com essas agências financeiras, cujos dirigentes eram nomeados (e, portanto, controlados) pelos próprios governadores;

c) por fim, a renegociação continuada do pagamento das dívidas com a União na prática significava sua postergação por tempo indeterminado.

A transformação desse cenário foi iniciada com o Plano Real (1994) e seu sucesso na estabilização monetária, que afetou significativamente a área fiscal no Brasil, em particular no que se refere às relações financeiras intergovernamentais. Primeiro, porque a redução drástica da inflação praticamente acabou com o floating que os governos subnacionais obtinham antes, bem como com a principal forma de alavancagem dos bancos estaduais. O resultado é que, sem o quadro superinflacionário presente anteriormente, as contas públicas estaduais desnudaram-se, revelando uma situação quase falimentar. A partir dessa fragilidade financeira, os governadores perderam poder vis-à-vis à União e foram, pouco a pouco, perdendo as "torneirinhas" financeiras que utilizaram maciçamente desde 1982, em especial as instituições financeiras estaduais.

A estabilização monetária brasileira, ademais, teve na âncora cambial um elemento-chave. Para tanto, era necessário atrair capitais externos, no mais das vezes por meio da elevação da taxa de juros. O efeito perverso desse mecanismo é bem conhecido: o crescimento exponencial do estoque da dívida pública, que passou de cerca de R \$ 60 bilhões em 1994 para mais de R \$ 624 bilhões no final de 2001. O total da dívida pública, que representava 35,8\% do PIB no início de 1998 , alcançou quase $50 \%$ no final de 1999 e girou em torno de $60 \%$ ao longo de 2002 .

O peso dos juros altos atingiu ainda mais os governos subnacionais, por conta de sua irresponsabilidade passada e fragilidade financeira atual. Nesse cenário, a negociação de um novo modelo de relações intergovernamentais se tornou questão de vida ou morte para os estados, numa situação de inferioridade para estes, sobretudo com a maior concentração de poder nas mãos da autoridade monetária do Banco Central. Boa parte do reordenamento das finanças públicas na era FHC teve esse cenário como pano de fundo.

\section{MUDANÇAS PÓS-94: A ESTABILIZAÇÃO MONETÁRIA E A CONSTRUÇÃO DE NOVAS INSTITUIÇÕES FISCAIS}

A estabilização monetária alcançada pelo Plano Real fortaleceu o presidente Fernando Henrique Cardoso, que pôde, principalmente no seu primeiro mandato, montar uma engenharia institucional que julgava adequada para modificar o ce- 
nário macroeconômico. Nesse sentido, contaram bastante a efetiva concentração da autoridade monetária no Banco Central (Sola, Garman e Marques, 2002) e o grande poder conferido ao Ministério da Fazenda, especialmente às suas Secretarias da Receita Federal e do Tesouro Nacional (Loureiro e Abrucio, 1999). Ao longo dos dois mandatos de FHC, o peso da Secretaria da Receita Federal (STN) foi variávelchave para o aperfeiçoamento da máquina arrecadatória e, de algum modo, para o crescimento da carga tributária no país, que passou de 22\% do PIB em 1994 para cerca de $34 \%$ em 2002, o patamar mais elevado da história brasileira, com o reforço da participação da União no conjunto do bolo tributário.

Para além de sua importância tradicional em qualquer Estado contemporâneo, especialmente em tempos de dificuldades financeiras, o Ministério da Fazenda fortaleceu-se de modo particular no governo FHC. Basicamente, esse poderio foi exercido por meio da liberação ou retenção de recursos orçamentários por parte da STN, que determinava, assim, o ritmo da implementação das políticas definidas por outros ministérios, de acordo com as necessidades do ajuste fiscal ${ }^{4}$. Igualmente por meio dos técnicos do Tesouro, a Fazenda atuou politicamente como mecanismo de controle dos outros ministérios nos quais os titulares foram nomeados como resultado das negociações para obter apoio no Congresso, fazendo com que eles se ajustassem às necessidades de controle das contas públicas (Loureiro e Abrucio, 1999) .

Finalmente, a STN, que centraliza a gestão de toda a dívida pública, também teve papel estratégico no processo de renegociação da dívida dos governos subnacionais, por conta da federalização desses débitos, detendo conseqüentemente informações sobre a situação das finanças de todos os entes da Federação.

Ainda no que tange ao papel da burocracia econômica, é essencial destacar que houve um processo de aprendizado incremental em relação às mudanças e aos erros cometidos ao longo da redemocratização. Muitos dos integrantes do staff da Fazenda, mesmo os que não eram de carreira, já tinham tido experiência em governos anteriores, participado de reformas importantes (como a criação da STN) e conhecido os limites político-econômicos postos ao reordenamento fiscal do país. Aqui, incrementalismo tem a ver com gradualismo, mas também com learning organization, traço distintivo não só dos grupos burocráticos estáveis, mas também dos altos funcionários que vêm de fora da administração pública.

O reforço do núcleo econômico e sua capacidade de aproveitar os caminhos

\footnotetext{
${ }^{4}$ É importante relembrar que no Brasil o orçamento aprovado pelo Legislativo é apenas autorizador, cabendo ao Executivo decidir sobre o ritmo e a quantidade de recursos a serem liberados ou não em cada item aprovado, em função das disposições do caixa e das necessidades de ajuste fiscal. Portanto, o Poder Executivo, por meio da STN, detém grande espaço de poder na execução orçamentária e, em inúmeras circunstâncias, o utiliza politicamente para garantir apoio dos congressistas (Gomes, 1999).

${ }^{5}$ No primeiro governo FHC, a orientação fiscalista do Ministério da Fazenda foi também difundida para os demais ministérios de modo informal, por intermédio da influência sobre o processo de nomeação de grande número de altos funcionários em outros ministérios, especialmente seus secretários executivos (Loureiro e Abrucio, 1999).
} 
abertos anteriormente, a prioridade dada à estabilização monetária e a força política oriunda do sucesso do Plano Real favoreceram o Governo Federal a realizar várias reformas político-institucionais no âmbito das finanças públicas. Destaque inicial para as que atingiram a questão federativa, cuja motivação vinculou-se ainda à crise financeira dos estados. Uma dessas medidas foi a aprovação de uma ampla renegociação das dívidas subnacionais, sob um contrato com maiores garantias de enforcement. Vinte e cinco estados assinaram um novo acordo com a União, amparado pela lei 9.496. O valor total do refinanciamento foi de 132 bilhões de reais (Mora, 2002: 31). Para tanto, os governos estaduais tiveram de assumir uma série de compromissos, incluindo a obtenção de superávit primário, aumento da arrecadação, privatização de empresas e/ou bancos, além de penalidades mais claras e efetivas, como a retenção dos recursos do Fundo de Participação dos Estados (FPE) - o que recebeu o aval constitucional do Supremo Tribunal Federal. Em todo esse processo, a STN, com delegação obtida pela lei aprovada no Senado, negociou e construiu os contratos de cada estado.

Os bancos estaduais também foram atingidos pelas transformações federativas. Houve extinções, privatizações e, sobretudo, o fim dos socorros compulsórios que marcaram o período anterior. Como resultado desse processo, dez bancos estaduais foram liquidados ou extintos, dezesseis foram transformados em agências de fomento, dez foram privatizados e quatro estão em processo de privatização. Para financiar este processo, o PROES (Programa de Incentivo à Redução do Setor Público na Atividade Bancária) desembolsou, até março de 2002, um pouco mais de 70 bilhões de reais (Mora, 2002: 53).

Duas mudanças na estrutura financeira da Federação merecem destaque especial: a aprovação de novas regras referentes ao endividamento público e a promulgação da Lei de Responsabilidade Fiscal. Pela sua importância, vale a pena examinálas em separado.

\section{RESTRIÇÕES MAIS SEVERAS AO ENDIVIDAMENTO PÚBLICO: O PAPEL DO CONGRESSO E DO SENADO}

O núcleo das mudanças na área fiscal no Brasil originou-se no Poder Executivo. Mas o Legislativo brasileiro também teve papel decisivo no processo. Embora esse aspecto tenha sido pouco marcado nos estudos sobre o tema, pode-se observar que, desde o início da década de 1990, o Congresso e, em particular, o Senado Federal - que tem a prerrogativa constitucional para estabelecer regras e limites ao endividamento público - vêm criando grande número de leis relativas a essa matéria. Em 1993, a Emenda Constitucional no 3 já restringira o endividamento público, só permitindo emissão de títulos para pagamentos de precatórios judiciais, ou seja, dívidas de particulares contra o Poder Público decididas em juízo. Como emitir títulos públicos para pagar precatórios significava, na prática, criar uma dívida nova, essa foi a única brecha deixada pela legislação para o financiamento dos governos subnacionais. Ela foi usada, ao máximo, como fonte "adicional" de 
financiamento público. E permitiu, inclusive, muitas irregularidades, objeto de farta cobertura da imprensa, levando à instalação de Comissão Parlamentar de Inquérito (CPI) em novembro de 1996.

Os escândalos acerca da emissão irregular de precatórios mostraram a profunda crise financeira em que se encontravam muitos governos subnacionais. Todavia, é preciso reconhecer que estes puderam agir assim porque sabiam que a elevada inflação dificultava sua percepção e fiscalização, bem como contavam com a conivência das autoridades encarregadas do controle do endividamento. Apesar de a CPI não ter resultado, pelo menos até o momento, na punição judicial dos envolvidos na emissão irregular de títulos precatórios, ela teve um efeito importante para disciplinar as finanças públicas no país: gerou a produção de regras cada vez mais restritivas para o controle do endividamento público.

Assim, em setembro de 1997, foi sancionada a lei 9.496/97, pela qual se estabeleceu um conjunto de critérios rígidos de refinanciamento da dívida pública mobiliária dos estados e do Distrito Federal. Em julho de 1998, o Senado baixou a Resolução 78/98, ainda mais rigorosa, que se tornou um marco de referência na consolidação das condições institucionais para o controle do endividamento público no país. Além de vedar a emissão de novos títulos públicos para governos já endividados, reduziram-se enormemente as possibilidades de financiamento público e transferiu-se poder para o Banco Central, facultando-lhe não mais encaminhar ao Senado Federal pedido de autorização de endividamento de governo com resultado primário negativo ${ }^{6}$.

Em dezembro de 2001, o Senado elabora duas novas resoluções, a 40/01 e a 43/01, que mantêm as condições da anterior (78/98), mas transferem do Banco Central para a Secretaria do Tesouro Nacional o poder de decidir sobre os pedidos de endividamento dos governos subnacionais. Antes de examinarmos o significado político desta delegação de poder e suas implicações para a accountability democrática, é importante marcar o caráter excessivamente rigoroso destas resoluções que proíbem, por exemplo, a emissão de títulos públicos por mais de dez anos (até 2010)7.

$\mathrm{Na}$ análise do comportamento do Congresso, particularmente do Senado, na produção de regras cada vez mais restritivas e severas ao endividamento público algumas dimensões merecem destaque especial. Mesmo sensível a pressões vindas dos governos estaduais (politicamente inevitáveis), essa casa foi se comprometendo cada vez mais, ao longo do mandato de FHC, com medidas pró-ajuste fiscal (Loureiro, 2001). A maioria dos senadores optou por uma nova "cultura de responsabilidade fiscal”, como se constatou nos discursos dos representantes estaduais do

\footnotetext{
${ }^{6}$ Para uma análise mais detalhada das ação do Senado nessa área bem como de seus impactos da Resolução 78/98 sobre as finanças públicas no país, ver Loureiro, 2001.

${ }^{7}$ Segundo alguns autores, a expansão do mercado primário de títulos estaduais e municipais, tal como ocorre nos Estados Unidos, poderia ser também fonte de financiamento público, pois não elevaria a já muito onerosa carga tributária do país (Toneto Jr. e Gremaud, 2000). Mas apostou-se mais no fato de que a falta de uma cultura de restrição orçamentária forte inviabiliza, no curto prazo, uma forma mais competitiva e responsável de os governos subnacionais se financiarem.
} 
governo e mesmo da oposição, em consonância com o que ocorria na opinião pública.

Por outro lado, o apoio à agenda da responsabilidade fiscal não significou mera submissão do Senado ao Executivo, envolvendo relações de negociação e barganha bem claras entre senadores, governadores estaduais e União. A delegação de poder ao Banco Central, por exemplo, ocorreu no bojo das negociações relativas à privatização dos bancos estaduais que criaram o Proes (Programa de Incentivo à Redução do Setor Público Estadual na Atividade Bancária).

\section{MUDANÇAS NAS POLÍTICAS ECONÔMICAS PÓS-99 E A LEI DE RESPONSABILIDADE FISCAL (LRF)}

A aprovação da Lei de Responsabilidade Fiscal (LRF) completa o ciclo das principais mudanças institucionais nas finanças públicas durante a Era FHC. O sucesso nessa empreitada se deveu a três fatores básicos. O primeiro foi o fortalecimento da União perante os governos subnacionais, como mostrado anteriormente, e, nesse novo cenário, o Governo Federal comandou as transformações nas relações financeiras federativas, tendo como leitmotiv o fim dos mecanismos predatórios de endividamento dos estados e municípios.

Em segundo lugar, instalou-se uma cultura política de responsabilidade fiscal tanto na opinião pública como nos atores políticos, como já apontado para os senadores (Loureiro, 2001). Por mais que tal clima de opinião dependa de instituições que solidifiquem esse novo padrão, será difícil, nos próximos anos, a adoção de uma prática populista e irresponsável perante as contas públicas.

Alguns fatores podem ter influenciado a formação desse consenso em torno da responsabilidade fiscal. Além do sucesso inicial do Plano Real e das pressões do mercado, exigindo maior "confiabilidade" para os investidores externos, também atuaram nessa direção a emergência de maior intolerância em relação à corrupção e de consciência mais clara dos danos que a insolvência dos governos geram à sociedade, tais quais as consequiências do não-pagamento de salários a funcionários (médicos, professores, policiais), greves, insegurança nas cidades, deterioração dos serviços públicos etc. Nessa linha contribuíram decisivamente os episódios dos precatórios, com grande repercussão em Pernambuco, Santa Catarina, Alagoas e São Paulo, e o da Máfia dos Fiscais, envolvendo a Prefeitura paulistana, os quais revelaram os resultados da irresponsabilidade fiscal em larga escala.

A pressão externa também teve grande impacto. Ela derivou de um conjunto de crises financeiras ocorridas neste período - México (1995), Ásia (1997) e Rússia (1998) —, como também da turbulenta desvalorização cambial, em janeiro de 1999. A crise russa já tinha levado o Congresso Nacional a aprovar um amplo programa de cortes orçamentários no final do primeiro período FHC, pois se dizia que ou se fazia isso, ou o Brasil entrava em bancarrota. O empréstimo articulado pelo FMI, por instituições multilaterais e pelos EUA, na casa dos 40 bilhões de dólares, simbolizava tal pressão. 
O ano de 1999 tornou-se, assim, ponto de inflexão importante não só na política cambial e monetária, mas também na área fiscal, com a adoção de uma forte restrição orçamentária e busca por superávits primários crescentes e sucessivos, acordados com o FMI. Em 2001, o superávit primário chegou à casa dos 3,5\% do PIB. Mesmo com esse resultado expressivo, a vulnerabilidade externa do país, fruto da aventura cambial e da aposta equivocada de que o mundo nos financiaria ad infinitum, ainda nos obrigará a muitos anos de sacrifício fiscal.

É nesse contexto de grandes constrangimentos externos que a LRF é apresentada ao Congresso e aprovada, em maio de 2000, com rápida tramitação e sem grandes modificações no projeto original encaminhado pelo Executivo. Cabe realçar que ela obteve elevado índice de votos favoráveis: 385 votos a favor, 86 contra e 4 abstenções.

A LRF procura estabelecer regras claras e precisas aplicadas às finanças de todas as esferas de governo. Trata principalmente da gestão da receita e da despesa governamentais, do aumento da transparência financeira, obrigando os governantes a prestar contas regularmente, e procura inculcar, com mais solidez, o planejamento como prática rotineira da administração fiscal. Entre os principais pontos da Lei de Responsabilidade Fiscal, os mais importantes são os seguintes:

a) Limitação de gastos com pessoal, estabelecendo não somente o quantopode ser gasto por cada nível de governo em relação à receita líquida, mas também - e aí está a sua novidade - o percentual equivalente a cada um dos Poderes, eliminando assim a distorção existente anteriormente, especialmente nos governos estaduais.

b) Reafirmação dos limites mais rígidos para o endividamento público estabe-lecidos pelo Senado Federal, indicando que o não-cumprimento será punido igualmente com mais rigor. O principal mecanismo de enforcement não é o judicial, como se destacou na imprensa, mas sim a retenção de transferências constitucionais e a proibição de obtenção de empréstimos e de convênios com o Governo Federal.

c) Definição de metas fiscais anuais e a exigência de apresentação de relatóriostrimestrais de acompanhamento. Foram criados também outros mecanismos de transparência, como o Conselho de Gestão Fiscal — a ser ainda constituído.

d) Estabelecimento de mecanismos de controle das finanças públicas em anos eleitorais.

e) Por fim, e mais importante, a proibição de socorro financeiro entre os níveisde governo, reduzindo o risco moral entre agentes públicos e destes para com os privados.

Várias das normas produzidas pelo Senado ao longo dos últimos anos serviram de base para a LRF, tida como marco no ajuste fiscal do país. Seus objetivos são prevenir déficits imoderados e reiterados, limitar a dívida pública a níveis prudentes, preservar o patrimônio líquido, limitar o gasto público continuado, estabelecer uma administração prudente dos riscos fiscais e oferecer amplo acesso das informações sobre as contas públicas à sociedade. Todos esses mecanismos estão atrelados a dois tipos de punição: um de cunho administrativo, limitando a ação do governante quando não cumprir adequadamente as regras; e outro de natureza 
político-jurídica, cujo objetivo é punir no âmbito político, com retirada de direitos políticos ou do governante do próprio cargo, procurando também estabelecer penas cíveis e criminais aos que desrespeitarem a LRF.

Um balanço ainda preliminar de dois anos e meio de vigência da LRF indica que, em grande medida, ela está sendo cumprida. Segundo informações oficiais, o total das despesas com pessoal dos Executivos estaduais no Brasil reduziu-se em termos reais em torno de $2,6 \%$. Isso ocorreu em função de um esforço de reestruturação do funcionalismo, do fim do pagamento de horas extras etc. Ainda no que se refere aos governos subnacionais, o esforço de redução de gastos tem permitindo que os estados apresentem superávits primários crescentes desde 1999. Mesmo com esse esforço fiscal, dados da STN mostram que o crescimento das despesas na área social acompanhou a elevação das receitas (em média 7\% ao ano nos estados), já que tais gastos estão, em sua maioria, constitucionalizados. Em outras palavras, não ocorreu uma redução dos welfares locais por conta do cumprimento da LRF.

Onde houve cortes foi na rubrica de investimentos, com impacto muito alto em infraestrutura e saneamento básico, principalmente.

Indo além do quadro geral da Federação, observa-se que a LRF foi implementada diferentemente em função de variações regionais, estaduais e partidárias. Dados sistematizados por Moraes (2002), relativos aos municípios brasileiros, trazem informações interessantes para os dois primeiros anos de vigência da LRF. A distribuição regional dos municípios que apresentaram déficits indica que o Sudeste apresentou o maior número de municípios com resultado primário negativo (689) em 2000, com destaque para Minas Gerais, com 392 municípios deficitários. Já em 2001, a Região Nordeste lidera o ranking, com 604 governos municipais em situação de déficit. O Sul destaca-se pela excelente melhora nas contas públicas locais, uma vez que 370 prefeituras conseguiram se ajustar no período de 2000/2001.

Com relação aos municípios que não têm conseguido apresentar regulamente os relatórios de gestão fiscal, tal como exige a LRF, indica-se que nas regiões Norte e Nordeste, $88 \%$ de seus municípios não entregaram os relatórios em 2000 nem tampouco em 2001. No Sul, em contraste, apenas $2 \%$ dos municípios não encaminharam seus relatórios em 2002 e 4\% não o fizeram em 2001. Além disso, nessa região também não houve nenhum caso de governo local que tenha deixado de apresentar relatórios nos dois anos consecutivos.

A análise dessa situação de irregularidade em relação às exigências da LRF, por estado, revela extrema concentração de problemas em quatro deles: Bahia, Maranhão, Pará e Piauí. Observa-se aí que a porcentagem de governos municipais irregulares atingiu mais de $62 \%$ no ano de 2000 . Em 2001 e no conjunto de 2000/2001, esses números foram de $39,2 \%$ e $62,4 \%$, respectivamente. Os problemas nos municípios desses estados explicam-se por fenômenos administrativos e, sobretudo, políticos clientelismo e ausência de controles institucionais, por exemplo - , que se tornam, assim, obstáculos à consecução dos objetivos da $\mathrm{LRF}^{8}$. Não será, portanto, a mera

\footnotetext{
${ }^{8}$ A capacidade de fiscalização e aplicação de sanções por parte dos Tribunais de Contas desses estados
} 
promulgação da lei ou a vontade de técnicos em Brasília que produzirá automaticamente os resultados fiscais esperados no conjunto dos governos locais.

No que se refere à dimensão partidária, dados do mesmo estudo (Moraes, 2002) indicam que todos os partidos melhoraram o desempenho fiscal de seus governos, independentemente da posição em relação ao Governo Federal (situação versus oposição), em particular no que tange ao cumprimento dos limites de gastos com pessoal (DP) frente à receita corrente líquida (RCL). Tais informações dão indícios de que está se formando uma cultura de responsabilidade fiscal entre os políticos no país. Chama a atenção, todavia, o fato de que o PT, então o maior partido de oposição, apresentou o maior crescimento do superávit primário entre 2000 e 2001, superando bastante o desempenho do conjunto dos municípios brasileiros e, inclusive, o dos governados pelo PSDB, partido do presidente da República.

Sintetizando o conjunto de transformações político-institucionais ocorridas na área fiscal, pode-se dizer que o Brasil viveu um duplo movimento no campo das finanças públicas ao longo da democratização. Por um lado, a partir do esgotamento do padrão de financiamento do Estado nacional desenvolvimentista e do início da redemocratização, configurou-se uma situação de crise fiscal estrutural, com causas provenientes do antigo modelo de intervenção estatal, das relações federativas, das dívidas interna e externa e da persistente inflação. Por outro, como processo pouco percebido, importantes transformações reordenaram e disciplinaram aos poucos as finanças públicas, especialmente no nível federal. Tais modificações formaram uma nova "camada geológica", que permitiu avanços posteriores.

A ênfase no caráter incremental das mudanças não deixa de reconhecer a existência de momentos de inflexão ou conjunturas críticas, como sublinha o quadro apresentado mais adiante. Apenas ressaltamos que as alterações não se processam de forma abrupta e total, já que diversas reformas resultaram de um aprendizado com os erros anteriores e até mesmo da utilização de estruturas criadas, quase que imperceptivelmente, ao longo da redemocratização. De fato, as conjunturas críticas podem permitir a abertura de canais que o incrementalismo não teve forças para tal; não obstante, o sucesso das inovações depende da percepção de que o reformismo é um processo.

Sob esse pano de fundo, ocorreram transformações no front intergovernamental, com a extinção ou privatização dos bancos estaduais, a renegociação das dívidas dos estados e a instituição de novas regras relativas ao endividamento público, ações voltadas contra o modelo predatório anterior, além de ter havido um fortalecimento das instituições econômicas do Executivo, como o Banco Central e o Ministério da Fazenda, as quais puderam coordenar melhor o funcionamento das finanças públicas federais, segundo os objetivos definidos pelos técnicos e aprovados politicamente pelo presidente da República.

revela um grande obstáculo à implantação do novo modelo fiscal. Pesquisa efetuada na Internet indicou que o site desse tribunal no Pará está inacessível. Os dos demais estados estão desatualizados ou não disponibilizam as informações sobre as contas municipais. Além da não-publicação dos resultados fiscais dos governos, a falta de pessoal qualificado e bem treinado nos Tribunais de Contas é outro agravante. 
Mas há ainda obstáculos sérios para se alcançar uma política fiscal sustentável, tais como: a não-aprovação de aspectos essenciais da Reforma Previdenciária, que permitiriam a redução de seu déficit crescente; o aumento da carga tributária sem uma verdadeira racionalização no campo das despesas; a centralização arrecadatória baseada em tributos de péssima qualidade, pois oneram demasiadamente a produção (contribuições sociais); e, sobretudo, uma política desequilibrada de juros, responsável por parte considerável da elevação do estoque da dívida pública no país. Eis o quadro que sintetiza as mudanças, as contratendências e ainda os limites à sustentabilidade da política fiscal.

\section{Principais mudanças político-institucionais na área fiscal no Brasil nas duas últimas décadas: tendências e contratendências ao ordenamento das contas públicas e ao ajuste fiscal}

\begin{tabular}{ll}
\hline Movimentos de ordenamento & Contratendências ou limites \\
\hline Década de $\mathbf{1 9 8 0}$ & \\
Crise dívida externa/esgotamento do & • Processo inflacionário \\
modelo financiamento que levam a: & • Caráter predatório das relações \\
- Fechamento Conta Movimento BB & financeiras: União e governos \\
- Extinção Orçamento Monetário & subnacionais (Constituição 1988) \\
- Criação da STN & \\
\hline
\end{tabular}

\section{Década de 1990/2002}

- Renegociação da dívida externa

- Permanência de alta inflação

- EC n 3 - restrições ao endividamento

- Revisão Constitucional (1994): FSE

\section{Estabilização monetária, 1994}

- Fortalecimento da União e do BC

- Lei 9496/97: Novo padrão de renegociação das dívidas estaduais

- Resolução do Senado n 78/98:

- Reformas da Previdência e Administrativa
- Política de juros elevados

- Déficits fiscais até 1999

- Estoque crescente da dívida pública com altos custos de rolagem

- Caráter limitado das reformas

\section{Mudanças pós-1999}

- Desvalorização cambial

- Limites do lado da receita: baixo

- CPMF/elevação carga tributária crescimento econômico

- Término das privatizações

- Superávits primários crescentes

- Déficits previdenciários crescentes

- LFR, maio 2000

- Centralização autoridade fiscal: STN

- Estoque elevado da dívida pública com altos custos de rolagem

- Resoluções Senado nº 40 e 43/2001 


\section{MUDANÇAS NAS INSTITUIÇÕES FISCAIS E ACCOUNTABILITY DEMOCRÁTICA}

Nesta seção, procuraremos examinar as mudanças institucionais na área fiscal à luz da problemática de accountability, enfocando em particular o desenho institucional produzido pelas resoluções do Senado destinadas a controlar o endividamento público e pela LRF.

\section{Regras legais de controle do endividamento público e accountability}

A partir da Resolução 78, de julho de 1998, o Senado criou restrições mais severas ao endividamento público no país e concedeu ao Banco Central (BC) o poder de emitir parecer conclusivo sobre os pedidos de endividamento de todos os entes da Federação. Em outras palavras, ele autorizou o BC a não lhe encaminhar os pedidos que não se enquadrem nas exigências legais. Configura-se assim uma clara delegação de poder, pela qual os senadores abriram mão da prerrogativa que o artigo 52 da Constituição Federal de1998 lhes outorga, de forma exclusiva, de autorizar operações financeiras para União, estados, municípios e empresas estatais, como também de estabelecer as condições de financiamento interno e externo e de fixar os limites de endividamento para todos os níveis de governo.

Em dezembro de 2001, novas resoluções do Senado (40 e 43) transferem essa delegação de poder das mãos do BC para a STN. Na opinião de alguns técnicos, a transferência para a STN justifica-se pela necessidade de centralizar nesse órgão o controle das finanças públicas e de manter o $\mathrm{BC}$ concentrado em suas atribuições específicas de gestor da política monetária, especialmente em uma eventual situação de formalização de sua autonomia operacional e política9 .

Interessa-nos aqui avaliar o significado político dessa delegação. Para tanto, é preciso considerar a complexidade das relações entre política e economia, ou, no caso específico, entre política e constrangimentos fiscais. De um lado, na condição de representante de seu estado na arena política nacional e percorrendo uma carreira que passa freqüentemente por cargos executivos estaduais, o senador brasileiro sofre pressões dos governadores, que muitas vezes foram seus colegas no Senado. Desse prisma político, recusar o endividamento para governos subnacionais é cortar uma das fontes fundamentais de reprodução dessa classe política. Por outro lado, ele é membro de um órgão que tem como função constitucional garantir o equilíbrio financeiro dos entes federativos.

É possível interpretar essa delegação de poder considerando que os senadores buscaram criar um mecanismo permanente para evitar pressões "irrecusáveis", ao mesmo tempo em que acolhem as necessidades de controle do endividamento. Por

\footnotetext{
${ }^{9}$ Entende-se por autonomia política do BC a capacidade de decidir sobre as metas da política monetária, enquanto autonomia operacional implica apenas a capacidade de gerir os instrumentos necessários para se alcançarem os objetivos definidos pelas autoridades eleitas (Sola, Kugelmas e Whitehead, 2002).
} 
intermédio das regras que dão ao BC e depois à STN a capacidade de emitir parecer conclusivo e de rejeitar os pedidos que não preencham as condições legais, não encaminhando tais pleitos para a Comissão de Assuntos Econômicos, o Senado transferiu porção considerável de seu poder decisório em matéria de endividamento para órgãos burocráticos.

Pode-se afirmar que, conhecendo a "fraqueza de sua própria vontade" ou sua própria incapacidade de resistir a pressões vindas dos governadores e de outros parlamentares, os senadores como que amarraram suas mãos e taparam seus ouvidos, pondo fim a um processo altamente politizado, resolvido caso a caso, e cujos custos tornavam-se cada vez mais elevados, especialmente frente aos constrangimentos externos que exigem o equilíbrio fiscal. Em outras palavras, a despolitização dos pleitos de crédito e sua transformação em matéria técnica, de alçada da burocracia, mostram como a racionalidade política se acomodou com os ditames do ajuste fiscal no interior do Senado (Loureiro, 2001). Ao fim e ao cabo, os senadores mais do que amarraram suas mãos; eles "lavaram" suas mãos.

Cabe perguntar, todavia: qual é o custo político dessa delegação? Ao despolitizar o processo decisório relativo ao endividamento público na suposição de que assim haverá um maior controle, esse desenho institucional tem efeitos consideráveis para a accountability democrática, na medida em que transfere as decisões para mãos de burocratas sem responsabilidade política. $\mathrm{Na}$ verdade, isso pode ser apenas a reprodução da velha e desgastada fórmula tecnocrática que predominou na gestão macroeconômica no Brasil e em outros países latino-americanos, não só nos regimes autoritários, mas igualmente nos períodos democráticos (Palermo e Novaro, 1996; Loureiro, 1997). O discurso que justifica essa prática pode ser assim resumido: "para evitar a interferência política, que atrapalha a melhor decisão técnica, a solução é o insulamento, caminho mais adequado para se alcançar maior eficiência e celeridade nos resultados das políticas ou reformas econômicas". É reduzido, com efeito, o espaço democrático do debate, da discordância e, o pior de tudo, do controle democrático, confinado que fica a uma só arena, exatamente a mais fechada de todas.

As práticas reiteradas no país de clientelismo e de irresponsabilidade fiscal não podem justificar restrições das formas democráticas de controle das finanças públicas. Afinal, não seriam os políticos, justamente por responderem aos cidadãos, os atores fundamentais na criação de uma cultura capaz de equilibrar os ditames do ajuste fiscal com as necessidades de gerar desenvolvimento, emprego e bem-estar social, muito mais do que os burocratas, por mais competentes e portadores de ethos republicano que sejam? Mais do que comparar a legitimidade desses agentes, o fundamental é saber que a transformação do modus operandi dos representantes políticos constitui o principal mecanismo de consolidação das reformas do Estado. Se a burocracia ajudar nesse processo, tanto melhor; o que não deve ocorrer é o alijamento dos políticos das decisões técnicas, visto que eles seriam, por natureza, “irresponsáveis”. 


\section{Lei de Responsabilidade Fiscal e accountability}

A aprovação da LRF foi considerada um marco no plano das relações federativas, não apenas porque objetivou melhorar a gestão fiscal de todos os níveis de governo, mas sobretudo em razão de apontar para um novo padrão de responsabilização mútua entre a União e os governos subnacionais. Em termos de accountability democrática, ademais, deve-se ressaltar que o processo, embora relativamente rápido em sua aprovação, foi marcado por intensa negociação e barganha ao longo dos últimos dois anos do primeiro governo FHC.

Não se pode esquecer, no entanto, que a pressão internacional vinculada à mudança do regime cambial foi uma variável exógena que atuou fortemente sobre o cálculo dos atores - aliás, tal qual ocorrera em outras modificações fiscais desse período. A variável externa aparece hoje, em maior ou menor medida, nas decisões dos parlamentos de qualquer país do mundo, não sendo ilegítima em si. Todavia, muitas vezes ela se coloca como uma força indiscutível e inegociável que pode afetar negativamente a accountability democrática.

A maior responsabilização entre os entes federativos foi uma conquista em prol do melhor desempenho econômico, pois evita o endividamento perverso que ocorria antes. Representou igualmente um avanço da democracia, uma vez que tornou mais transparente e responsiva a decisão dos governos em relação aos demais, ao estabelecer, por exemplo, a obrigatoriedade de apresentação de relatórios periódicos e impor sanções a quem não cumprir as regras. Permitiu, assim, equacionar melhor a chamada "tragédia dos comuns" que caracteriza as relações intergovernamentais em uma federação.

Ressalte-se, porém, que esse mecanismo básico de accountability federativo está mais preocupado em controlar passo a passo os governos subnacionais do que em discutir regularmente com os atores envolvidos na gestão fiscal do país. Tal modelo tem reforçado a concentração do poder nas mãos da burocracia do Executivo federal, que centraliza o processo de controle, geralmente deslegitimando os reclamos dos outros entes federativos. Desse modo, há o perigo de que o objetivo de transparência contido explicitamente na lei acabe mais por funcionar como instrumento de controle do Governo Federal sobre os governos subnacionais do que se tornar uma real prestação de contas por parte dos representantes eleitos ao Legislativo e aos cidadãos.

A accountability democrática ganharia mais força se a LRF colocasse em funcionamento o mecanismo do Conselho de Gestão Fiscal previsto em seu arcabouço jurídico, mais precisamente no artigo 67. Seu principal objetivo seria harmonizar e coordenar os entes da Federação, constituindo-se num fórum que reuniria os diversos atores federativos, da sociedade civil e representantes dos poderes, os quais avaliariam e discutiriam a implementação da lei, podendo até propor a modificação da legislação, caso julgassem necessário. Em resumo, seria uma arena na qual os principais agentes negociariam ajustes no processo e compartilhariam decisões.

O funcionamento do Conselho de Gestão Fiscal depende de uma lei que o regulamente. É bem verdade que o Executivo Federal enviou proposta nesse sentido ao 
Congresso - projeto de lei 3.744/2000 — , mas também está claro que não houve vontade política para que essa legislação avançasse em sua tramitação. $\mathrm{Na}$ ausência dessa regulamentação, todo o poder foi concentrado na STN, que vem editando normas gerais de consolidação das contas públicas (Vignoli et al., 2002: 192-194).

O que explica a posição adotada pelo Governo Federal é o predomínio de uma visão em que a variável democrática da negociação e do controle é percebida como algo que pode afetar negativamente os resultados da política fiscal. O temor da equipe econômica vincula-se à possibilidade de retorno do antigo modelo federativo, marcado pela irresponsabilidade predatória dos governantes subnacionais. Trata-se de uma concepção fiscalista que, no fundo, crê que só uma lei geral que ultrapasse mandatos e governos, pode garantir o equilíbrio fiscal. Em suma, uma forma de sepultar a política, em sua acepção mais ampla, no terreno das finanças públicas.

A história de irresponsabilidade fiscal do país e o peso da gramática clientelista são razões que não podem ser negligenciadas. Não obstante, da maneira como está definida a Lei de Responsabilidade Fiscal, coloca-se em questão o direito à mudança das políticas governamentais. O que está em jogo aqui é a relação sempre necessária de equilíbrio entre governo e Estado, de tal modo que é preciso, sim, ter regras estáveis no essencial, mas também deve haver um espaço para negociações e mudanças que exprimam a dinâmica democrática do voto.

Foi também seguindo essa ótica que, mediante um processo de delegação quase irrestrita de poderes ao BC, o Brasil adotou durante quatro anos (1994-1998) uma política cambial errada que, impermeável às críticas, não pôde ser aperfeiçoada ao longo do caminho. O resultado foi duplamente ruim: para a economia e para a democracia.

\section{CONSIDERAÇÕES FINAIS}

Argumentamos no texto que houve reformas fiscais no país, efetuadas ao longo de mais de duas décadas, embora permaneçam problemas e desafios cruciais para a sustentabilidade da política fiscal. Em boa medida, esse processo se deu de forma incremental, e não por um modo abrupto e linear de mudança. Houve avanços e recuos nas propostas ou objetivos inicialmente estabelecidos e amplas negociações com diferentes atores políticos.

Argumentamos também que o modelo incrementalista ou gradual é o mais compatível com democracias de tipo consensual, como o sistema presidencialista de coalizão existente no Brasil. O incrementalismo requer um Executivo forte do ponto de vista de governança, ou seja, do ponto de vista da competência da burocracia governamental, para implementar de forma efetiva a agenda do governo. Por outro lado, ele é a expressão de um arranjo institucional no qual o Executivo é politicamente limitado ou constrangido, ou seja, forçado institucionalmente a levar em conta e negociar com outros atores políticos relevantes e mesmo com grupos organizados na sociedade.

Cabe ressaltar que democracia consensual não significa Executivo fraco e tam- 
pouco fragmentação de poderes sem responsabilidade mútua. O que se requer é um governo forte em termos de capacidade de coordenação, formulação, implementação e avaliação de políticas, mas institucionalmente constrangido, e um sistema político, especialmente nas esferas congressual e federativa, com poder de controle, mas responsável perante o processo decisório.

O padrão de reformas econômicas no Brasil correspondeu, em parte, ao modelo incrementalista. Isso pôde ser percebido em aspectos tributários e em certos momentos da negociação federativa, em especial. Em outros momentos, contudo, prevaleceu uma visão majoritária quanto ao processo decisório, cujo caso exemplar foi a condução da política monetária e cambial pelo Banco Central. Assistiuse a uma convivência entre estes dois modelos e, segundo o aferido neste trabalho, quanto mais consensual o processo, mais efetivas foram as políticas.

No caso das reformas fiscais, constatamos a existência de negociações continuadas entre os atores políticos no Legislativo e nos governos subnacionais. No entanto, o resultado final contido nos desenhos institucionais que têm servido de base para o controle do endividamento público e para a LRF não caminhou na mesma direção. Restabeleceu-se, assim, a dicotomia entre a concentração de decisões em fóruns insulados do Executivo e os requisitos democráticos de responsabilidade política estendida.

Contrapondo-se à nossa visão, parte da literatura ressalta que é preciso levar em conta o custo político e financeiro das negociações sobre o ajuste fiscal. Do nosso ponto de vista, esta é apenas uma possibilidade e não uma condição necessária. Além do mais, é sempre conveniente lembrar que a falta de negociação pode dificultar a implementação das reformas, gerando, por sua vez, seus próprios custos. A questão é como incorporar a negociação nas políticas de reformas de tipo incremental, considerando sempre que os atores podem mudar suas posições, alterando a relação inicial de custo-benefício desse processo.

A LRF é exemplo bastante significativo de que mudanças substantivas em uma área de política pública, particularmente difícil, como a fiscal, podem, sim, advir de transformações institucionais, mas igualmente derivam de novas coalizões de interesses e são geradas sob uma nova cultura política. Em outras palavras, o sucesso da LRF, a despeito de seu conteúdo politicamente "amargo", é resultado de uma mudança induzida por um grupo no poder que conseguiu alterar, paulatinamente, as preferências da maioria, num processo que tende a sedimentar uma nova forma de organizar as finanças públicas brasileiras. As instituições são necessárias para garantir a continuidade desse movimento, só que elas não podem, sob o ponto de vista democrático, "amarrar" completamente as ações futuras, proibindo que correções de rota e/ou mais negociações sejam feitas.

O governo Lula representa grande teste para as duas concepções de reforma. No terreno fiscal, a rolagem da dívida dos governos subnacionais é colocada como o maior fantasma, uma vez que se teme o retorno do padrão populista e irresponsável que vários governadores e prefeitos adotaram ao longo da redemocratização. Entretanto, a legitimidade dos pleitos dos governantes locais deriva de um fato tecnicamente comprovado: o comprometimento com o pagamento da dívida torna-se cada 
vez mais insustentável e reduz a possibilidade de investimentos, sobretudo porque os contratos foram assinados com a perspectiva de um melhor desempenho da economia, variável esta que certamente escapa do controle dos governos estaduais ${ }^{10}$.

Estamos, portanto, diante de dois diagnósticos: o primeiro ressalta o caminho irresponsável dos governos estaduais durante a redemocratização e afirma a necessidade de restrições orçamentárias fortes para evitar o retorno ao modelo predatório de relações intergovernamentais; o segundo mostra que, sem crescimento econômico, o padrão vigente de ajustamento estadual é insustentável. Ambos os argumentos estão corretos, por mais paradoxal que possa parecer. A solução passa, a um só tempo, pela criação de normas e valores vinculados à responsabilidade fiscal e pelo estabelecimento de condições políticas e econômicas capazes de viabilizar tal cenário.

A invenção desse (novo) modelo só pode ocorrer por intermédio de uma estratégia incremental que parta de um arcabouço mínimo de regras de convivência e de arenas democráticas de negociação, a partir das quais os entes federativos realizem barganhas públicas e transparentes, de modo a responsabilizar todos por seus atos; que se utilize das lições do passado e das instituições existentes, aperfeiçoando-as gradualmente e com parcimônia; e que seja ainda capaz de compatibilizar os objetivos de crescimento e ajustamento, uma vez que o fiscalismo e muito menos o populismo orçamentário não são desejáveis.

Seguindo essa linha, propomos o seguinte encaminhamento à rolagem da dívida dos estados e às instituições vinculadas ao controle do endividamento. É preciso, primeiramente, estabelecer um compromisso pela restrição orçamentária responsável, tal qual exposto nos principais pontos da LRF - embora o "crescimento" dessa lei tenha embutido nela aspectos que vão além do arcabouço mínimo necessário, amarrando questões que não deveriam estar lá. Em segundo lugar, o único meio de garantir a sustentabilidade das dívidas estaduais é o crescimento econômico, e não a mera permissão de mais gastos públicos. Assim sendo, para se renovar o pacto federativo no plano fiscal, União e estados devem se unir a fim de aprovar medidas capazes de melhorar o desempenho econômico no curto e médio prazo. As reformas tributária e previdenciária são essenciais nesse sentido, bem como uma política mais agressiva para as exportações e medidas capazes de favorecer o aumento da poupança e do crédito no país. Tais ações são deliberadas e aprovadas em arenas nacionais, mas como algumas delas dependem da anuência do Congresso Nacional, os líderes regionais têm de se comprometer a apoiá-las, pois disso depende o crescimento e, por conseguinte, a sustentabilidade do endividamento subnacional.

\footnotetext{
${ }^{10}$ Segundo Mônica Mora: “(...) o crescimento substancial da economia é condição sine qua non para assegurar a sustentabilidade da dívida estadual no longo prazo. Mesmo com elevadas taxas de crescimento do PIB não é certo que os estados alcançarão os resultados desejáveis. Simultaneamente, (...) o controle dos estados sobre o resultado primário não depende exclusivamente do seu esforço fiscal. Ao contrário do que se possa imaginar, os estados possuem uma pequena margem de manobra sobre as variáveis da receita" (Mora, 2002: 65).
} 
Todas essas ações vão exigir uma forma mais articulada e negociada de relacionamento federativo. A criação do Conselho de Gestão Fiscal e o aprimoramento da atuação do Senado são passos importantes para essa estratégia. O incrementalismo, como dito antes, requer arenas democráticas e sujeitas à responsabilização pública. Isso deve ser feito concomitantemente ao reforço da governança, isto é, da qualidade da burocracia, dando-lhe um papel formulador e implementador de destaque, mas sem que ela se torne o único núcleo das decisões. A LRF e as finanças intergovernamentais, em resumo, precisam ser melhoradas por decisões técnicas e políticas.

O caminho do incrementalismo talvez seja percebido como mais difícil. Só que ele é o único capaz de evitar tanto o insulamento burocrático como o clientelismo desbragado. Sua dinâmica passa por um modelo mais responsável em relação ao desempenho e às demandas dos cidadãos. Foi Max Weber o primeiro a mostrar que o desafio das democracias contemporâneas encontra-se na integração da lógica da eficiência com a lógica democrática, e não na sua separação. Decerto que a tensão sempre existirá na relação entre política e técnica, mas a via mais adequada, no entanto, é procurar estabelecer ganhos mútuos entre democracia e eficiência. É o que tentamos comprovar neste artigo, tanto do ponto de vista normativo como, principalmente, pela análise da experiência brasileira recente.

\section{BIBLIOGRAFIA}

ABRANCHES S. (1988). "Presidencialismo de coalizão: o dilema institucional brasileiro". Revista Dados, 3(1). Rio de Janeiro: Iuperj.

ABRUCIO, F.L. (1998). Os barões da Federação: os governadores e a redemocratização brasileira. São Paulo: Editora Hucitec.

ABRUCIO, F.L. (1999). "O longo caminho das reformas nos governos estaduais: crise, mudanças e impasses”. In MELO, M. (org.). Reforma do Estado e mudança institucional no Brasil. Recife: Fundação Joaquim Nabuco/Editora Massangana.

ABRUCIO, F.L. (2000). Os laços federativos brasileiros: avanços, obstáculos e dilemas no processo de coordenação intergovernamental. Tese de Doutorado. São Paulo: Universidade de São Paulo, Departamento de Ciência Política (mimeograf.).

ABRUCIO, F.L. e FERREIRA COSTA, V.M. (1998). Reforma do Estado e o contexto federativo brasileiro. Pesquisa, ${ }^{\circ}$ 12. São Paulo: Fundação Konrad Adenauer.

AFFONSO, R. (1995), “A questão tributária e o financiamento dos diferentes níveis de governo”, in AFFONSO, R. e SILVA, P. L. (orgs.). A Federação em perspectiva: ensaios selecionados. São Paulo: Fundap/Unesp.

ALEM, Ana Cláudia e GIAMBIAGI, Fábio (2000). Finanças públicas: teoria e prática no Brasil, Rio de Janeiro: Campus.

ALESINA, A., Roubini, N. e Cohen, G. (1997). Political cycles and the macroeconomy. Cambridge University Press.

ALMEIDA, M. H. T. (1999). "Negociando a reforma: a privatização das empresas públicas no Brasil”. Dados. Revista de Ciências Sociais, 42 (3).

BANCO MUNDIAL (1997). O Estado num mundo em transformação. Relatório sobre o desenvolvimento mundial. Washington, D.C.

BARBOSA, Fábio e GIAMBIAGI, Fábio. "O ajuste fiscal de 1990-1993: uma análise retrospectiva”. In: Revista Brasileira de Economia, jul/set 1995, vol. 49, n 3: 521-543. 
BRESSER-PEREIRA, L. C. (1993). "Economic reforms and economic growth: efficiency and politics in Latin America”. In: Bresser-Pereira, Maravall and Pzreworski (1993). Economic Reforms in New Democracies. Cambridge University Press.

BRESSER-PEREIRA, L. C. (1996). Crise econômica e reforma do Estado no Brasil: para uma nova interpretação da América Latina. São Paulo: Ed. 34.

CAIDEN, G. (1991). Administrative reform comes of age. Walter de Gruyter. Berlin/New York.

CAMPOS, I. W. (2002). O Impasse da reforma tributária na era FHC. Tecnocracia versus elite industrial: o triunfo da arrecadação sobre a produção. Tese de Doutoramento apresentada na FFLCH da Universidade de São Paulo (mimeog.)

CEPAL. La política fiscal em América Latina, 1999 (série Seminários e Conferências).

COUTO, C. e ABRUCIO, F.L. (1999). Arenas políticas e agenda econômica: os caminhos institucionais do Real. Paper apresentado na XXIII Reunião da ANPOCS. Caxambu.

DIÁRIO DO SENADO FEDERAL (1997). Relatório final. CPI dos Títulos Públicos. Brasília, agosto.

DILLENGER, W., PERRY, G. e WEBB, S. (2000), Macroeconomic management in decentralized democracies: the quest for hard budget constraints in Latin America. Trabalho apresentado na reunião da LASA, março.

FIGUEIREDO, A. e LIMONGI, F. (1999). Executivo e legislativo na nova ordem constitucional. Rio de Janeiro/São Paulo: Editora FGV/Fapesp.

GARMAN, C, LEITE, C. e MARQUES, M. (1998). Impactos da relação Banco Central versus bancos estaduais no arranjo federativo pós-1994: análise à luz do caso BANESPA. XXII Encontro Anual da ANPOCS, Caxambu, outubro.

GIAMBIAGI, F. (1997). “A crise fiscal da União: o que aconteceu recentemente? Revista de Economia Política, 17 (1): 65, janeiro-março.

GOMES, J. M. (1999). A definição do gasto público: aspectos institucionais e disputa política. Tese de mestrado. São Paulo: Eaesp/FGV.

GOUVEA, G. (1994). Burocracia e elites burocráticas no Brasil. São Paulo: Paulicéia.

LIJPHART, A. (1999). Patterns of democracy. Government forms and performance in thirty-six countries. Yale University Press.

LOUREIRO, M. R. (1997). Os economistas no governo. Gestão econômica e democracia. Rio de Janeiro: Editora FGV.

LOUREIRO, M. R. "Instituições, política e ajuste fiscal: O Brasil em perspectiva comparada”. In: Revista Brasileira de Ciências Sociais, 2001, vol. 47, $\mathrm{n}^{\circ}$ 16, pp. 75-96.

LOUREIRO, M. R. E ABRUCIO, F. (1999). "Política e burocracia no presidencialismo brasileiro: o papel do Ministério da Fazenda no primeiro governo Fernando Henrique Cardoso". Revista Brasileira de Ciências Sociais, outubro, pp. 69-89.

MAINWARING, S. (1993). “Democracia presidencialista multipartidária: o caso do Brasil”. São Paulo: Lua Nova. Revista de Cultura e Política, 28/29.

MELO, M. (2002). Reformas constitucionais no Brasil. Rio de Janeiro: Editora Revan.

MORA, M (2002). Federalismo e Dívida Estadual no Brasil. Textos para discussão, nº 866. Rio de Janeiro: Ipea.

MORAES, T. C. (2002). "Um estudo sobre a Lei de Responsabilidade Fiscal: problemas e resistências políticas”. Relatório do Programa Iniciação Científica - CNPq / NPP/EAESP-FGV.

MUSSA, M. e SAVASTANO, M. “The IMF approach to economic stabilization”. Fundo Monetário Internacional, jul. 1999, IMF Working Paper (WP/99/104).

NORTH, D. (1981). Structure and change in economic history. New York/London: Norton.

O”DONNELL, G. (1998). “Accountability horizontal e novas poliarquias”. In: Lua Nova, $\mathrm{n}^{\circ}$ 44: 28 54. OCDE (2001). Estudos Econômicos do OCDE - Brasil (2000-2001). Rio de Janeiro: OCDE, Editora FGV.

PARLEMO, V. (2000). "Como se governa o Brasil? O debate sobre instituições políticas e gestão do governo". Dados, 43 (3): 521-558.

PALERMO, V. e NOVARO, M. (1996). Politica y poder en el gobierno de Menen. FLACSO/ Grupo Editorial Norma. 
POCOCK, J. G. A. (1975).The Machiallevian moment. Princeton University Press.

PRZEWORSKI, STOKES e MANIN (1999). Democracy, accountability and representation. Cambridge University Press.

RAMOS, Ana Paula. "A política fiscal do Plano Real e o ajuste fiscal para 1999-2001". Revista de Economia Política, out./dez. 2001, vol. 21, nº 4 (84).

REZENDE, Flávio(2002). "Por que as reformas administrativas falham?" Revista Brasileira de Ciências Sociais, vol. 17, $\mathrm{n}^{\circ}$ 50: 123-142

REZENDE, Fernando (1995). “Federalismo fiscal no Brasil”. Revista de Economia Política, vol. 15 (3).

ROUBINI, N. E SACHS, J. (1989). "Political and economic determinants of budget deficits in the industrial democracies”. European Economic Review, 33: 903-938.

SCHICK, A. (1993). "Governments versus budget deficits”, in Weaver, K. e Rockman, B., Do institutions matter? Governmnet capabilities in the United States and abroad. Washington, D. C.: The Brookings Institution.

SOLA, L., KUGELMAS, E. e WHITEHEAD, L. (orgs.) (2002). Banco Central. Autoridade política e democratização - um equilíbrio delicado. Rio de Janeiro: Editora FGV.

SOLA, L., GARMAN, C. e MARQUES, M. (2002). "Central Banking, democratic governance and politcal authority”. IN: SOLA, L., KUGELMAS, E. e WHITEHEAD, L. (orgs.) (2002), op. cit.

STARK, D. e BRUSTZ, I. (1998). "Enabling constraints: fontes institucionais de coerência nas políticas públicas no pós-socialismo", Revista Brasileira de C. Sociais, vol. 13, n 36, fevereiro, pp. 13-39.

TSEBELIS, G. (1990). Nested games: rational choice in comparative politics. Berkeley: University of California Press.

TONETO, JR. e GREMAUD (2000). “Por que não um mercado de títulos municipais?”. Informações FIPE, 239, agosto.

VIGNOLLI, F. et alli (2002). A Lei de Responsabilidade Fiscal comentada para municípios. São Paulo: Editora FGV.

VELLOSO, Raul. "Balanço da situação das contas públicas". In: REIS VELLOSO, João Paulo dos (org.) (1999). A crise mundial e a nova agenda de crescimento. Rio de Janeiro: José Olympio.

WEAVER, K. e ROCKMAN, B. (1993). Do institutions matter? Government capabilities in the United States and abroad. Washington, D. C.: The Brookings Institution. 